\title{
Professors' and Undergraduate Students' Perceptions and Attitudes Toward the Use of Code-Switching and Its Function in Academic Classrooms
}

\author{
Raghad Y. Alkhudair ${ }^{1}$ \\ ${ }^{1}$ Qassim University, Department of English Linguistics and Translation, Saudi Arabia \\ Correspondence: Raghad Y. Alkhudair, Qassim University, Department of English Linguistics and Translation, \\ Saudi Arabia. E-mail: Raghadalkhudair@outlook.com
}

Received: August 1, 2019 Accepted: August 25, 2019 Online Published: October 13, 2019

doi:10.5539/ijel.v9n6p160 URL: https://doi.org/10.5539/ijel.v9n6p160

\begin{abstract}
This paper aims to determine the usefulness and functions of code-switching in the classroom when used by both lecturers and students. The study was conducted at a Saudi university campus and follows a quantitative approach using sets of questionnaires to collect the data. Then, the data were analyzed using SPSS (Statistical Package for the Social Sciences). Based on the analysis, the given study shows that professors and students consider code-switching from English into Arabic in the classroom as a beneficial instrument in enhancing the learning process. That is because it allows otherwise insurmountable problems for two-way communication in the L2 target language (English) to be overcome. Also, the findings of the current study reveal a range of positive attitudes toward using code-switching in two ways, Saudi-English immersion classrooms. Specifically, the majority of the professors use this technique in certain situations to achieve a better understanding by the students. In the same vein, students in this study show huge acceptance and prove how such a phenomenon has worked as a learning facilitator. It is hoped that the results of this study will be useful for professors and researchers investigating the importance of code-switching in the classroom.
\end{abstract}

Keywords: code-switching, bilingualism, English teaching, English learning

\section{Introduction}

English enjoys a high status around the world. It is the language of choice in many domains such as business, entertainment, and currently, it is also the medium of communication of education in many countries. Language plays an important role in education; many scholars have reflected on the importance of language in the learning process. As Carrasquillo and Rodriguez (1996) asserted, language forms a key part of life and is integral to societal systems and groups. Thus, English in schools of most countries is considered an essential subject. As TESOL (2008, p. 1) affirms "English is seen less and less as a "foreign" language, and more as an additional language".

In Saudi Arabia, for example, learning English has found huge acceptance because it is required in many fields such as science and engineering. Some schools teach their students through English as a medium of communication while others set English as a primary subject among other Arabic-based subjects. In academic settings, English has particular importance to a great number of students who majored in English at major at universities where English is the main language of instruction. These students come from many different types of L2 English backgrounds and have a wide range of proficiency levels. Accordingly, many of them face various obstacles in learning English as a foreign or a second language (i.e., not their native language or L1). Therefore, professors face several difficulties in delivering subject matter effectively because students use two (or more) common languages with different levels of comprehension and proficiency in each. We can consider this as a common problem that occurs in bilingual communities. Indeed, the majority of the world's English speakers are bilingual (Grosjean, 2010), which means that using two (or more) languages has become a common phenomenon in the modern world.

As Burden (2001) has stated, code-switching represents an effective technique when teaching in an L2, such as in ESL. Students often find code-switching a straightforward and interesting approach to acquiring a foreign language due to the sense of comfort it produces by reducing their affective filter (Krashen, 1982) which may encourage them to continue their learning instead of dropping out. Furthermore, Benson (2001) has defended the 
use of mother tongue in language learning, stating that "the use of a familiar language to teach beginning literacy facilitates an understanding of a sound-symbol or a meaning-symbol correspondence" he also added, "student learning can be accurately assessed in bilingual classrooms" (p. 56). Indeed, when students can express what they wish to say, their instructors can then check what they have learned, what requires further instruction and identify students who require further help.

Thus, students in EFL/ESL classrooms need assistance of professors when they face issues in understanding a specific teaching point. This assistance can take various forms; some lecturers repeat the problematic word or phrase using different words or using a high or low intonation while others tend to code-switch to the student's L1 to explain. Nonetheless, code-switching as a linguistic strategy has several different aspects that must be taken into consideration. For instance, code-switching could be perceived positively or negatively according to the context and the attitude of the language instructor (who may or not agree with its use; in the total immersion approach, only the L2 (target language is permitted). This paper contributes to an examination of the influence of code-switching in bilingual ESL/EFL classrooms to measure its degree of effectiveness and usefulness for language learning.

\section{Literature Review}

Bilingual societies are rich in various types of linguistic phenomena; code-switching represents an often-encountered practice that appears in different settings. Numan and Carter (2001) have defined code-switching as the phenomenon where speakers switch from one particular language to a different language within a discrete utterance. Usually, the languages employed in code-switching are the mother tongue (L1) and a foreign language (L2). Code-switching commonly occurs in English as a second language (ESL) or English as a foreign language (EFL) classrooms. Such classrooms are considered bilingual environments. In recent years, code-switching has been viewed as a meaningful linguistic phenomenon in EFL/ESL classrooms and has attracted considerable attention. The status of code-switching has also become a matter of debate for many researchers who investigate language use and language learning in the classroom environment. A large number of studies have described the role of code-switching in different settings such as educational contexts, social environments, and so on.

As globalisation has developed, speakers from societies around the world have become increasingly faced with multilingual language contexts and multilingual interaction has attracted many researcher's attention. Indeed, there are many instances where elements of one language become associated with another language in the case of loan words (Thomason, 2001). The term linguistic operations mostly refer to operations such as lexical borrowing, transferring, interference, calquing, code-switching and code-mixing. Code-switching represents one of the most noticeable phenomena that has emerged through bilingual and multilingual societies due to the influence of lingua franca and globalisation.

\subsection{A Closer Look at Code-Switching}

Code-switching or alternating between two (or more) languages in a discrete utterance is a complex linguistic phenomenon that is carried out according to specific language rules. Code-switching provides a useful window into one of the main challenges of understanding bilingual speech. For Brice and Brice (2000), code-switching encompasses the speaker's use of entire sentences, short phrases, and loan words borrowed from another language that they incorporate into a specific utterance.

Gumperz (1982) has defined code-switching as "the juxtaposition within the same speech exchange of passages of speech belonging to two different language/grammatical systems or sub-systems" (p. 59). A more recent definition of code-switching by Sebba, Mahootian, and Jonsson (2012) is that code-switching occurs when a speaker naturally alternates between two languages or more in their speech.

Generally speaking, second language acquisition (SLA), language acquisition, and language learning research employ code-switching in relation to either language learners' or bilingual speakers' cognitive-linguistic capabilities or learner/classroom-focused pedagogical practices where two (or more) languages are used (Romaine, 1989). Moreover, Gardner-Chloros (2009) mentioned that "switching from language to language is crucial martial for our understanding of how languages both processed and understood in the brain" (p.101). Therefore, code-switching can be investigated across many aspects; some research focuses on how the human brain deals with this process while others look for the reasons and functions for its existence in specific situations. Although we cannot concretely investigate these two aspects mentioned above in this paper, we can consider code-switching in terms of its role in language learning in ESL/EFL classrooms.

In the literature, code-switching is categorized into several different types; Hoffman (1991) asserted four types of code-switching: (i) inter-sentential, (ii) intra-sentential, (iii) tag switching. First, inter-sentential code-switching 
refers to when a language switch happens at the boundaries between discrete sentences; fluent bilingual speakers are the main users of this type. Next, intra-sentential code-switching refers to a shift between languages that occurs in mid-sentence with no hesitations, no interruptions and no pauses to indicate a change. The speaker mostly performs this type unconsciously. The third type stated by Hoffman (2014) is tag switching where speakers insert a tag question or phrase from one language into another regardless of the syntactic rules; for example, in Bahasa Indonesia, one could say: 'It's hot, ya kan?' (It's hot, isn't it?).

The multiple purposes of intra-sentential code-switching were detailed by Muysken (2000) who mentioned: (i) the insertion of a lexical item from one discrete language into another language's structure; (ii) altering between language structures; (iii) $t$ lexicalization of a congruent nature involving lexical items from various inventories of lexis into a common grammatical structure.

In the same vein, Blom and Gumperz (1972) suggested two other types of code-switching: (i) situational code-switching and (ii) metaphorical code-switching. They defined situational code-switching as when a speaker changes or switches language according to the immediate situation. For example, a young speaker is likely to use a formal register when addressing an older interlocutor while if a younger speaker is addressing an interlocutor of the same age and status, they will tend to use a more informal register. Whereas metaphorical code-switching indicates that a speaker's choice of language can imply a specific symbolic meaning; in other words, the language chosen is used to suit the message being given. A quote attributed to Charles V (1500) the Holy Roman Emperor illustrates this by showing his attitudes towards certain languages as holy, romantic or used to build male solidarity or crude or bestial: "I speak Spanish to God, Italian to women, French to men, and German to my horse" (p. 10). Later, Gumperz appears to realize the imperfection of describing switching as either situational or metaphorical. By 1982, Gumperz had introduced a new term for code-switching: conversational code-switching.

A number of other researchers discuss different types of code-switching such as: (i) borrowing; (ii) calque (in which the speaker translates sentences without the use of appropriate syntax); and (iii) inter-sentential (which is mentioned by many other linguistics and researchers) (Hughes, Shaunessy, Brice, Ratliff, \& McHatton, 2006). In this investigation, however, all types of code-switching will be referred to as code-switching regardless of which type is used by the student or the professor.

\subsection{The History of Code Switching}

In the history of the development of code-switching as a linguistic strategy, the interest in the study of code-switching arose in the early 20th century when Espinosa (1917) first described a mixture of speech in the dialogues of New Mexicans (as cited in Pollard, 2002). More recently, Nilep (2006) reported on one of the most important early American studies by George Barker (1947) who describes the use of language among Mexican Americans in Tucson, Arizona. He posits that it is likely that Spanish was used for spoken conversations among members of families, while formal conversations with Anglo Americans were most likely to employ English (even though all interlocutors are proficient in Spanish).

In addition to the previous studies related to code-switching, Weinreich (1953) examined interactions among interlocutors using code-switching in order to identify common practices within bilingual speech communities in terms of how language contact impacts on language use. Weinreich explained the use of code-switching by which a bilingual individual can speak two separate linguistic varieties, which ideally they employ on separate occasions.

Moreover, Muysken (2000) pointed out the earlier attempts made in order to determine the nature of code-mixing. As in the 1960s when Lehtinen and Clyne, in their study of a Finnish-English bilingual corpus recorded by one speaker "in order for intra-sentence code-switching to be possible at all, there must exist in the two languages some constructions which are in some sense similar so that certain syntactic items from each language are equivalent to each other in specific ways" (p. 82). Muysken (2000) considers code-mixing to represent an intricate arrangement of other processes by which language contact occurs: lexical triggering, transfer and convergence. Consequently, the turning point in the study of code-switching is often considered to be from 1972 when Blom and Gumperz published their paper "Social meaning in linguistic structures" (cited in Myers-Scotton, 1993). By 1972, the term code-switching was well attested in the literature.

In recent years, As Algarin-Ruiz (2014) Gray, Johnson, and Jennifer Kish-Gephart (2018) mentioned, there has been an increasing amount of literature investigating the nature of code-switching in various fields. Recently, new researchers from CUNY College in New York City had used the term "trans-languaging" to describe this phenomenon in a different context: daily life. The meaning of this term is very similar to code-switching, with a few variations. Trans-languaging indicates the action in which people coexist while utilizing more than one language in their daily life. Although the researchers have made it clear that this is not the same as code-switching, the definition still gives us an extended vision of what this phenomenon (Code-Switching) is in the life of a 
bilingual person.

\subsection{The Relationship Between Bilingualism and Code Switching}

An individual who is able to speak in a single language only is considered monolingual while someone who is able to speak in two languages is bilingual. The term bilingualism was first introduced by Bloomfield (1935) who defines bilingualism as the ability to use two languages or to have "native-like control of two languages" (p. 56). According to Malmkjaer and Anderson (1991), a bilingual is a person whose ability in both languages is the result of natural processes of acquisition such as upbringing in a bilingual home or of finding themselves in a situation in which more than one language needs to be used (i.e., in a lingua franca context) but who has not learnt either language formally as a foreign language. A bilingual may be classified as a natural bilingual if they learned their L2 as a child or as a concurrent bilingual when their L1 and L2 were acquired in their natural environment. Next, a secondary bilingual refers to when one has learned an L2 during an educational context (Hoffman, 1991). Thus, the study of bilingual individuals' behaviour is a complex area. Code-switching appears frequently in bilingual communities and is mainly considered a vital feature of bilingualism since the switching cannot occur unless it happens among more than one language. Code-switching is a linguistic strategy that only relatively proficient bilinguals can use (Becker, 2001). Similarly, Heredia and Altarriba (2001) reported that code-switching is used by bilingual speakers to shift from one language to another language, and this is especially true in the case that both languages tend to be used in their usual context, following functional and grammatical maxims and is a rule-governed, complex phenomenon.

Part of the evidence supporting the view of code-switching as an intrinsic part of bilinguals' environment is summed up by Redouane (2005) who wrote that the most predominant linguistic phenomenon found in bilingual speakers' interactions is code-switching. Furthermore, code-switching is a common occurrence within the bilingual classroom where both professors and students share the same languages. As Crystal (1997) suggested, code-switching occurs when a bilingual individual alternate between two languages during their speech with another bilingual interlocutor.

However, despite code-switching being seen as a natural aspect of bilingual speech (Palmer, 2009), bilingualism is also perceived as an additive or subtractive language process, as explained next. The former involves acquiring linguistic items and fluency in an L2 without losing key L1 skills (Lamberts, 1975) while the latter relates to the growth of fluency and vocabulary in the L2 causing decreases in fluency and vocabulary in the L1, whereby the original language is replaced as the speaker's 'primary language'. Thus, given the evidence mentioned so far, we can assert that code-switching is a hallmark of bilinguals' behaviour since many studies relate code-switching to bilingual spoken communication.

\subsection{The Nature and Functions of Code-Switching}

\subsubsection{Social Code-Switching}

Many studies described the different reasons for a bilingual person to switch from language to language. Code-switching is a phenomenon is related to the field of sociolinguistics, which studies the language events that occur in social contexts. In the field of sociolinguistics, many investigators have attempted to define the relationship between code-switching and ethnicity, class and other social factors. As Auer (1984) points out, social situations are not simply reflected in code-switching but code-switching is used to create new social-linguistic contexts.

Numerous researchers have explained the social functions of the use of code-switching. For Wardhaugh (2006), the speaker's reasons to employ code-switching are determined by the speaker's immediate linguistic interlocutors as well as the speaker's desire for acceptance and solidarity with these interlocutors. Moreover, Wardhaugh (2006) added that code-switching between languages may also allow a speaker to "assert power; declare solidarity; maintain a certain neutrality when both codes are used; express identity; and so on" (p. 50). In certain situations, a speaker's use of code-switching may be a way to create linguistic solidarity with individuals with a common ethnocultural identity.

Other sociolinguistic studies have shown that code-switching has a crucial role in social purposes and its use is not necessarily an indicator of linguistic incompetence. For example, Zentella (1997) found that speakers often start speaking in the language they are most comfortable speaking in and switch to a newcomer's preferred language. Consequently, code-switching may serve to enhance many linguistic functions (Nilep, 2006). For example, code-switching can be used to mark the selection of conversational turns ( $\mathrm{Li}, 1998$; Cromdal, 2001) make refusals more easy to accept (Bani-Shoraka, 2005; Li, 2005) and achieve repair of misunderstandings (Auer, 1995; Sebba $\&$ Wooten, 1998) or highlight dis-preferred utterances (Li, 1998; Bani-Shoraka, 2005). Also, other research has 
highlighted how code-switching indicates aspects of a speaker's identity or background that are pertinent to a dialogue in progress (e.g., Li, 1998, 2002; Gafaranga, 2001).

\subsubsection{Code-Switching in the Classroom}

However, code-switching is predictable in the classroom where the professor and students share the same languages. It happens whether between the professors and students or between the students themselves. The study of code-switching role in the classroom has been investigated in many parts of the world. In the last few decades, the use of code-switching in bilingual classrooms has become an area of great interest and has become an area of contention in many areas, especially in the field of linguistics and sociolinguistics. Some of this research claimed that code-switching harms the educational process and the language of the speaker themselves while others suggest that code-switching has a positive effect.

For Palmer (2009), many multilinguals perceive code-switching as signifying linguistic inadequacy or 'weakness' and many bilingual teachers are against code-switching in their classroom. However, many educators appear to be unaware of how to benefit student's L1 in teaching an L2, and this misunderstanding of the process often reduces the benefits of code-switching, considering the occurrence of code-switching in the classroom as a sign of failure that must be corrected.

However, other educators argue that the reason students employ code-switching is to recompense for their lack of proficiency in the L2 and that may not be fully proficient in either language (their L1 or L2). Most of the problems related to this perspective derive from perspectives on language proficiency; a student who is allowed to code-switch in the classroom is often considered to be on course to achieve only a weak proficiency in English. As Hammink and McLaughlin (2000) stated, "the use of code-switching is often considered a low prestige form, incorrect, poor language, or a result of incomplete mastery of the two languages." (p. 89). Yet, there are always two different sides to the same coin; while some research views code-switching as a negative phenomenon, many others consider code-switching a valuable tool in the ESL/EFL classroom. Huerta-Macias and Quintero (1992), for example, assert that code-switching not only enhances communication in pedagogical terms but also helps bilinguals to develop (and maintain) their languages.

Hughes et al. (2006) noted that to use code-switching effectively, students require a significant understanding of the two language's linguistic cultures and a deep understanding of the underlying structures and purposes of the two language systems. Indeed, code-switching is often found in many societies and contexts, defining the variations between speakers' culturally, generationally, and technologically related backgrounds. Together, these studies outline the role of code-switching in serving different social and educational purposes. Thus, code-switching is not reserved for specific situations or settings; it can be adapted to accomplish a wide range of different linguistic and social goals. Code-switching's positive or negative aspects rely on how and when it is used and why. The current study will seek to identify the need for code-switching in academic classrooms and how both professors and students can benefit from it as a learning strategy.

\section{Methods}

This article is a case study which adopts the quantitative approach in collecting and analyzing the data. This section focuses on the subjects' recruitment and materials employed for collecting the data. 3.1 Subjects

Two groups of subjects took part in the survey. The sample cohort for the quantitative case study includes female students $(\mathrm{n}=60)$ and professors $(\mathrm{n}=20)$ who were selected in order to evaluate their attitudes and views. The former included English-major students enrolled in the Department of English Language and Translation at Qassim University. Only female students have participated in the study because of the context of cultural restrictions adopted by Saudi community where co-education is not allowed. The students were selected randomly from different English levels, ranging from levels 1-4. The researcher has handed in the questionnaire to those professors who cooperated with the researcher and they administered the tool for those who were voluntarily agreed to fill in the questionnaire. The total number of the participants was 516 students and only 60 participants who sent back the questionnaire to the researcher. The latter group was comprised of lecturers teaching English courses as per the study plan of the college in immersion classes at Qassim University. Their teaching experience varies from 3-10 years. The total number of lecturers on[ the campus was 60 and the respondents were $20(33.3 \%)$.

\subsection{Data Collection Instrument}

The data was collected using two separate sets of questionnaires circulated among the two groups: professors (see Appendix A), for students (see Appendix B). The questionnaire was developed by the researcher on the basis of the previous studies reviewed in the literature and according to the requirements of the study context. In the current study, two structured questionnaires were used. These comprised of closed-ended questions to collect data in the 
form of pre-defined responses. The pre-defined responses gathered the respondents' views on the usefulness and functions of code-switching in the classroom when used by both lecturers and students. The questionnaires were designed in a form of dichotomous Likert-scale responses (i.e., 'agree' or 'disagree') and the respondents answered the survey questions by selecting one of the two options.

The questionnaire created for the professors (Appendix A) investigates two aspects:

(i) Professors' perceptions and attitudes toward the use of code-switching; and

(ii) The reasons leading to the use of code-switching in the classroom.

The first part (questions 1-7) deals with the professors' attitudes and views about using code-switching in terms of its use by both English professors and students. It also investigates their attitudes toward using code-switching in academic settings. The second part of the professors' questionnaire (questions 8-16) examines the functions performed by professors' code-switching in the language classroom. Specifically, they investigated the nature of and reasons why they use code-switching. The latter is structured identically to the first part of the questionnaire. The student questionnaire seeks to examine the same objectives and functions as the professors' questionnaire but from the students' perceptions. The only difference between the questionnaires lies in the distribution of the questions. Specifically, in the student questionnaire, questions 1-12 evaluate their perceptions and attitudes toward code-switching while questions 13-15 explore the reasons for their use of code-switching in the classroom.

\subsection{Data Collection Procedure}

In relation to the research questions, the research procedure was designed as follows. Initially, the researcher carried out pilot questionnaires to check the reliability and validity of the data collection instrument. (who did not take part in the main study) answered the survey without any major difficulties. Then, the researcher the questionnaire has been distributed to the students and the professors for the main research. The questionnaires were administered in different ways. Students completed their questionnaires under the supervision of their professors after a brief introduction to the aims and goals of the study. The professors' questionnaires were administrated via e-mail. Then, the researcher statistically analyzed the data using the Statistical Package for the Social Sciences (SPSS) to compile percentages on each of the respondents' responses. The quantitative approach to data collection was used in this study to describe, test, and objectively examine the data to enhance the accuracy and generalizability of the results and allow cause-and-effect relationships to be identified (Burns \& Grove, 1987).

\subsection{Reliability}

The two sets of questionnaires were developed in accordance with the requirements of validity and reliability for use in the data-collection process. Specifically, data's reliability was measured using Cronbach's Alpha in order to examine the internal consistency of the instrument used in the present study. The result showed that professors' questionnaires had the reliability index of .80 while the students' questionnaire had a reliability index of .79, which indicates the surveys have adequate consistency and allows the survey results to be generalized to other contexts.

\section{Findings}

This section provides an overview of the results of the subjects' responses in the form of percentages for each response. The responses are divided into two main parts. The first shows that professors and students expressed mixed attitudes towards code-switching. The second part presents the nature and functions of code-switching as suggested by the data.

\subsection{Perceptions and Attitude Toward Code Switching}

\subsubsection{Professors' Perceptions and Attitude Toward the Use of Code-Switching}

In order to accomplish the main purpose of the study (evaluating the professors' perceptions on their use of code-switching and their attitudes toward students' use of code-switching in the classroom), the professors were asked "Do you agree or disagree with professors speaking your mother tongue as well as English in the classroom?" the responses showed that $82.4 \%$ of professors agree and $17.6 \%$ disagree. Additionally, $76.5 \%$ believe that code-switching enhances the learning process although $23.5 \%$ disagree. This means that the majority of the professors consider code-switching a useful pedagogical tool to enhance student-learning processes. It is evident when considering the percentage of professors who think code-switching may lead to the weakness of students' proficiency in English as shown in the table below. 
Table 1. Professors' perceptions and attitude toward the use of code-switching in the classroom by both educators and students

\begin{tabular}{|c|c|c|}
\hline Expressions & Agree & Disagree \\
\hline Do you agree or disagree with code-switching strategy used by professors in the classroom? & $82.4 \%$ & $17.6 \%$ \\
\hline I think code-switching strategy enhances the learning of the English language. & $76.5 \%$ & $23.5 \%$ \\
\hline I think code-switching strategy prevents the students from thinking and exploring by themselves. & $52.9 \%$ & $47.1 \%$ \\
\hline I think using a mixture of languages leads to the weakness of students' English. & $41 \%$ & $59 \%$ \\
\hline I prevent students to switch since that will ruin their English vocabulary. & $29.4 \%$ & $70.6 \%$ \\
\hline allow my students to switch to Arabic when they do not know the equivalents words in English. & $79.6 \%$ & $20.4 \%$ \\
\hline
\end{tabular}

\subsubsection{Students' Perceptions and Attitude Toward the Professors' Use of Code-Switching}

The responses to the question "Do you agree or disagree with professors speaking your mother tongue as well as English in the classroom?" indicate that $81.6 \%$ of the students agreed with professors using code-switching in the classroom and $83.7 \%$ considered it as a valuable tool. Based on the analysis, the majority of the students expressed their satisfaction with professors' use of code-switching for a number of reasons: (i) 77.6\% stated that code-switching helps them to participate and be active in the class; (ii) $79.6 \%$ believe code-switching facilitates and speeds up their learning because the professor will explain and clarify matters in their native language. On the other hand, $51 \%$ of the students believe that professors' use of code-switching will negatively affect their language proficiency and fluency in English.

Table 2. The perceptions of students toward the use of code-switching in the classroom

\begin{tabular}{|c|c|c|}
\hline Expressions & Agree & Disagree \\
\hline Do you agree or disagree with professors speaking your mother tongue as well as English in the classroom? & $81.6 \%$ & $18.4 \%$ \\
\hline $\begin{array}{l}\text { I see code-switching as a valuable tool in the classroom since it helps me to understand the complicated matter } \\
\text { in an easy way. }\end{array}$ & $83.7 \%$ & $16.3 \%$ \\
\hline When the professor switches from English to Arabic, it affects my English language proficiency. & $51 \%$ & $49 \%$ \\
\hline When the professor switches from English to Arabic, he or she makes the lesson more complicated. & $24.5 \%$ & $75.5 \%$ \\
\hline Code-switching enhances my learning of the English language. & $71.4 \%$ & $28.6 \%$ \\
\hline
\end{tabular}

Table 3. The student's attitude toward the use of code-switching

\begin{tabular}{|c|c|c|}
\hline Expressions & Agree & Disagree \\
\hline When the professor switches from English to Arabic, it helps me to participate and be more active in the class. & $77.6 \%$ & $22.4 \%$ \\
\hline Using code-switching by professors saves my time and efforts to look for aspecific meaning. & $79.6 \%$ & $20.4 \%$ \\
\hline I prefer professors using a mixture of different languages. & $65.3 \%$ & $34.7 \%$ \\
\hline The professors encourage us to use code-switching insome situation. & $57.1 \%$ & $42.9 \%$ \\
\hline Using code-switching in the classroom makes me sure that I am not losing any idea or information. & $71.4 \%$ & $28.6 \%$ \\
\hline When the professor switches from English to Arabic, I consider him as a nonprofessional person since he or she violates & $24.5 \%$ & $75.5 \%$ \\
\hline English classroom rules. & & \\
\hline $\begin{array}{l}\text { I think when the professor switches from English to Arabic, he or she makes me feel that I am not sufficient enough to } \\
\text { understand English. }\end{array}$ & $36.7 \%$ & $63.3 \%$ \\
\hline
\end{tabular}

\subsection{The Nature and Reasons Behind the Occurrence of Code-Switching in the Classroom}

This section will answer the study's main question "Why professors and students code-switch in the classroom?"

\subsubsection{Professors' Reasons to Code-Switch in the Classroom.}

Regarding the data shown in Table 4, most of the professors switch from English to Arabic in order to meet the students' interest. That is, $86.5 \%$ switch to Arabic to translate and clarify difficult terminology that students may find hard to understand while 35.3\% sometimes switch from English to Arabic to provide additional (perhaps unnecessary) explanation on some points to assure that the students understand the point accurately or to give extra information. For example, if a student does not know the English equivalent of an Arabic word or if they feel nervous or lack the confidence to express themselves in English. Furthermore, when professors were asked if they switch in order to boost student participation, $70.6 \%$ disagreed.

The majority of professors do not switch from English to Arabic in situations where they feel that is unnecessary. For example, when responding to item 8 "I only switch to Arabic when I want to direct my students, like "open the 
book" or "write your assignment", $94.1 \%$ responded in the negative.

Table 4. The professors' responses with a percentage of the reasons behind the occurrence of code-switching in the classroom

\begin{tabular}{|c|c|c|}
\hline Expressions & Agree & Disagree \\
\hline I only switch to Arabic when I want to direct my students, like "open the book", 'write your assignment'. & $94.1 \%$ & $5.9 \%$ \\
\hline $\begin{array}{l}\text { I perceive ease of expression and more students are taking part in the classroom talk when I and my students switch } \\
\text { to Arabic in some situations. }\end{array}$ & $59.5 \%$ & $40.5 \%$ \\
\hline $\begin{array}{l}\text { I use code-switching strategy to clarify information that is hard to deliver to the student when I use the English } \\
\text { language. }\end{array}$ & $64.7 \%$ & $35.3 \%$ \\
\hline I encourage the students to switch to Arabic in some situations. & $58.8 \%$ & $41.2 \%$ \\
\hline I use code-switching strategy to provide (more) explanation of some points. & $35.3 \%$ & $64.7 \%$ \\
\hline I use code-switching strategy to translate and clarify difficult vocabulary. & $86.5 \%$ & $13.5 \%$ \\
\hline Code-switching strategy makes the students understand what I am sufficiently explaining. & $76.5 \%$ & $23.5 \%$ \\
\hline I use code-switching to make the lesson and the lecture easier to follow. & $82.4 \%$ & $17.6 \%$ \\
\hline I use code-switching strategy to boost students to participate. & $58.8 \%$ & $70.6 \%$ \\
\hline
\end{tabular}

\subsubsection{Students' Reasons to Code-Switch in the Classroom}

The major concentration of the study was to investigate why professors switch from English to Arabic and was this technique used for the enhancement of the learning process or for other purposes. Accordingly, the students also were asked about the functions of their switching between the two languages in order to compare their answers with their professors' answers. The findings showed $73.5 \%$ of the students switch from English to Arabic only when they are unable to express themselves in English. Whereas $77.6 \%$ switch to Arabic when they want to say words that they have not exposed yet to their equivalent in English.

Table 5. The functions of students' switching in the classroom

\begin{tabular}{lll}
\hline Expressions & Agree & Disagree \\
\hline I use code-switching in the classroom when I'm unable to English express myself in. & $73.5 \%$ & $26.5 \%$ \\
I feel more comfortable when I communicate with my English professors in. & $75.5 \%$ & $24.5 \%$ \\
I switch to Arabic when I say words that I did not expose to English their equivalent in. & $77.6 \%$ & $22.4 \%$ \\
\hline
\end{tabular}

\section{Discussion}

Several prior studies have highlighted disagreements about professors' use of code-switching in the classroom. For example, Palmer (2009) found that many multilingual speakers posit that code-switching demonstrates linguistic inadequacy or 'weakness' and many bilingual tutors make efforts to suppress code-switching in their classroom. The professors in Palmer's study implemented a reward system to discourage students from using code-switching in their classrooms because the professors believed code-switching reflects corrupt language usage. However, the present paper seeks to examine the evidence for such claims and assess whether code-switching has a beneficial impact on the learning process. This is demonstrated in the current study findings where the researcher found that professors perceive that the use of code-switching may lead to inadequacy in the target language and make students rely on native language expressions to compensate the inefficiency in the target language. The findings of the present study go in line with Hammink and McLaughlin (2000) who demonstrate that reliance on code switching may lead to poor proficiency in the second language.

Accordingly, if we consider the responses of the professors and students to the initial questionnaire items (1) 'Do you agree or disagree with professors speaking your mother tongue as well as English in the classroom?'; and (2) 'I think speaking the student's mother tongue, as well as English in the classroom, helps them learn English more effectively', we find these data provide positive feedback by both professors and students toward the use of code-switching. This is strong evidence that suggests code-switching is not only acceptable but also that it is frequently used by tutors and students. Therefore, it appears that both groups benefit from code-switching because it supports both professors and students in accomplishing communicative and educational goals. Therefore, the present study's results are at odds with previous findings (i.e., Palmer, 2009), which consider code-switching as both undesirable and non-effective in the classroom.

Based on the analysis of the questionnaires, we can conclude the functions of the use of code-switching by 
professors in two-way immersion classroom in a few points. First, code-switching facilitates clarification. As shown in Tables 1, 2, 3 and 4 above, professors mostly switch from English to Arabic to clarify points that may be unclear to the students. For example, when a student has misunderstood the lecturers' requirements for a specific task. Then, the lecturer will try to clarify their point by switching to Arabic in order to avoid misinterpretation.

Second, the results reveal that code-switching facilitates professors to explain unfamiliar terminology and complex concepts in specific classroom situations. For example, when English terms had to be interpreted or translated into Arabic to allow students to better comprehend the point and develop their English vocabulary. Code-switching also appears helpful in introducing students to English idioms for the first time. The students may understand the meaning of the idiom's individual words but not its illocutionary force (e.g., the individual words in the idiom 'break a leg' may be understood by students but its illocutionary force - wishing someone good luck - may not).

Therefore, in light of the findings discussed above, the claim that using code-switching will weaken students' English proficiency is not supported by the evidence. On the contrary, the use of code-switching between the student's L1 and the target language in particular situations does not negatively affect the learning process it appears to provide students with a more in-depth understanding of the subject matter.

Overall, the evidence presented in this section supports the notion that code-switching is a valuable tool in the academic classroom and helps to enhance the learning process. Specifically, code-switching satisfies the students' need for more clarification or explanation of particular points in which their English proficiency is lacking. Using code-switching in a balanced way is likely to provide a balanced knowledge of both languages without causing appreciable weaknesses in one or the other. Accordingly, professors must better understand how and when they should switch to the students' native language. Thus, I maintain that professors must be better trained on how and when to use code-switching in their early-level English classes while the students are still new to this practice while in the case of high-level English classes, it appears better to limit code-switching to give the students the opportunity to stretch their abilities and work independently to explore and search for the meaning of unknown terms. Specifically, students who are allowed to use code-switching in the classroom environment may be better able to express their knowledge and ideas. Thus, students who are not allowed to code-switch could face embarrassment when they try to explain themselves but are faced with particular vocabulary barriers. Such situations will likely lead to poorer participation and interaction in the class. Also, this pressure is likely to affect students' confidence in the target language.

Consequently, it would be better to allow students to switch to their L1, at which point the professor can explain to the student the appropriate English vocabulary and check the students' understanding of it. This is considered to be a more effective way to learn in which the professor presents new lexis in English and then asks the student to repeat it (also known as drilling). As Canagarajah (1995) mentioned, repetition is one of the effective teaching methods while using code-switching. Also, Skiba (1997) suggests that students use code-switching because they are unable to express themselves in the target language, it serves to facilitate continuity of speech instead of causing language. Thus, code-switching represents a supporting method of communication in both classrooms and social interactions. Therefore, code-switching serves to enhance communication as a tool to transfer meaning and information.

Regarding what has been argued above, we should consider code-switching strategy as a double-edged sword. Since it serves the pedagogical process if it aimed to transfer meaning and clarify unfamiliar or difficult information to the students which cannot be held in the second language. The side effects will occur when the professor use the students' native language to explain the second language. That is when the professor most of the time abandons the use of the second language and allows the students to speak in their native language freely without any attempts to produce spoken sentences in English. This will diminish the ability of the students to understand and speak in English.

\subsection{Conclusion}

In the context of English language instruction, code-switching occurs frequently in Saudi classrooms. Although some experts disagree with code-switching (because they perceive it as non-beneficial for developing students 'proficiency in the target language and weakens their ability to become fluent in English), this paper set out to examine the empirical evidence on the effectiveness of code-switching in academic classrooms and evaluate professors' and students' points of view on code-switching. By returning to the research questions posed at the beginning of this study, the data supports the notion that code-switching is a beneficial strategy that should be used in classrooms when insurmountable barriers to communication and/or understanding occur in the exclusive use of the target language. Also, the findings revealed a range of positive attitudes toward using code-switching in two-way immersion classrooms. 
Accordingly, it is hoped that this study's results will be useful for language professors and other researchers investigating this area. Furthermore, the reader should bear in mind that this study was based on a single setting (Qassim University, Saudi Arabia) and thus the findings may not be completely generalizable to other contexts.

\subsection{Limitations and Recommendation for Future Studies}

This study has raised some limitations which could be addressed by future research. The study has adopted only one instrument (i.e., a questionnaire). Future studies may triangulate the data collection tools by conducting a structured-interview with the participants. The second limitation is the construction of the questionnaire which contains only two scales which restrict the participants' answers. It is recommended to include Likert-five scales to give the participants more options to answer. Another limitation is that only female students participated in the study due to the cultural barriers of the context of the study which segregates males from female students. Therefore, future studies may focus on involving males to come up with more reliable and valid results.

\section{References}

Algarin-Ruiz, K. M. (2014). Code Switching: A Tool in the Classroom. Master's Theses. Retrieved from http://digitalcommons.brockport.edu/ehd_theses/393

Bani-Shoraka, H. (2005). Language Choice and Code-Switching in the Azerbaijani Community in Tehran: A conversation analytic approach to bilingual practices. Doctoral Thesis, Uppsala University Publications.

Becker, R. R. (2001). Spanish-English Code Switching in A Bilingual Academic Context. Reading Horizons, $42(2), 100-115$.

Benson, E. (2001). The Neglected Early History of Codeswitching Research in the United States. Language \& Communication, 21, 23-36. https://doi.org/10.1016/S0271-5309(00)00012-4

Blom, J. P., \& Gumperz, J. (1972). Social meaning in linguistic structure Code-switching in Norway. In J. Gumperz \& D. Hymes (Eds.), Directions in sociolinguistics. New York: Holt, Rinehart and Winston.

Bloomfield, L. (1935). Language. London: Allen \& Unwin.

Brice, A., \& Brice, R. (2000). Language in the classroom: Comparisons of four bilingual environments. South Africa: Asha.

Burden, P. (2001). When Do Native English Speaking Professors and Japanese College Students Disagree about the Use of Japanese in the English Conversation Classroom? The Language Teacher. Online. Retrieved from http://www.jalt-publication.org/tlt/articles/2001/04/burden.

Burns, N., \& Grove, S. K. (1987). The Practice of Nursing Research Conduct Critique and Utilization. WB Saunders: Philadelphia.

Canagarajah, A. S. (1995). Functions of Code switching in ESL Classrooms: Socializing Bilingualism in Jaffna. Journal of Multilingual and Multicultural Development, 16(3), 173-195. https://doi.org/10.1080/01434632.1995.9994599

Carrasquillo, A., \& Rodriguez, V. (1996). Language minority students in the mainstream classroom. England: Multilingual.

Cromdal, J. (2001). Can I be with? Negotiating play entry in a bilingual school. Journal of Pragmatics, 33(4), 515-543. https://doi.org/10.1016/S0378-2166(99)00131-9

Crystal, D. (1997). English as a Global Language. Cambridge: Cambridge University Press.

Gafaranga, J. (2001). Linguistic identities in talk-in-interaction: Order in bilingual conversation. Journal of Pragmatics, 33(12), 1901-1925. https://doi.org/10.1016/S0378-2166(01)00008-X

Gardner-Chloros, P. (2009). Code-switching. Cambridge: Cambridge University Press. https://doi.org/10.1017/CBO9780511609787

Gray, B., Johnson, T., Kish-Gephart, J., \& Tilton, J. (2018). Identity work by first-generation college students to counteract class-based microaggressions. Organization Studies, 39, 1227-1250. https://doi.org/10.1177/0170840617736935

Grosjean, F. (2010). Bilingual: life and reality. London: Harvard University Press. https://doi.org/10.4159/9780674056459

Gumperz, J. J. (1982). Discourse strategies. Cambridge: Cambridge University Press. https://doi.org/10.1017/CBO9780511611834 
Hammink, J. E., \& McLaughlin, B. (2000). A comparison of the code-switching behavior and knowledge of adults and children. Austin: University of Texas.

Heredia, R., \& Altarriba, J. (2001). Bilingual language mixing: Why do bilinguals code-switch? Current Directions in Psychological Science, 10(5), 164-168. https://doi.org/10.1111/1467-8721.00140

Hoffman, A. (1991). An introduction to bilingualism. Longman. https://doi.org/10.17848/9780585255859.Ch1

Hoffmann, C. (2014). Introduction to bilingualism. London: Routledge. https://doi.org/10.4324/9781315842035

Huerta-Macías, A., \& Quintero, E. (1992). Code-switching, bilingualism, and biliteracy: A case study. Bilingual Research Journal, 16(3-4), 69-90. https://doi.org/10.1080/15235882.1992.10162638

Hughes, C. E., Shaunessy, E. S., \& Brice, A. R. (2006). Code switching among bilingual and limited English proficient students: Possible indicators of giftedness. Journal for the Education of the Gifted, 30(1), 7-28. https://doi.org/10.1177/016235320603000102

Krashen, S. (1982). Acquiring a second language. World Englishes, 1(3), 97-101. https://doi.org/10.1111/j.1467-971X.1982.tb00476.x

Li, W. (1998). Building Ethnoburbia: The Emergence and Manifestation of the Chinese Ethnoburb in Los Angeles' San Gabriel Valley. Journal of Asian American Studies, 2, 1-28. https://doi.org/10.1353/jaas.1999.0009

Macaro, E. (1997). Target language, collaborative learning and autonomy. Clevedon: Multilingual Matters.

Malmkjær, K., \& Anderson, J. M. (1991). The Linguistics Encyclopedia. London: Routledge.

Muysken, P., Díaz, C. P., \& Muysken, P. C. (2000). Bilingual speech: A typology of code-mixing. Cambridge: Cambridge University Press.

Myers-Scotton, C. (1993). Duelling Languages. New York, NY: Oxford University press.

Nilep, C. (2006). Code switching in sociocultural linguistics. Colorado Research in Linguistics, 19(1), 1-22. Retrieved from https://philarchive.org/archive/NILCSI

Numan, D., \& Carter, D. (2001). Teaching English to speakers of other languages. Cambridge: Cambridge University Press. https://doi.org/10.1017/CBO9780511667206

Ovando, C. J., \& Combs, M. C. (2012). Bilingual and ESL classrooms: Teaching in multicultural settings. New York: McGraw-Hill.

Pollard, S. (2002). The benefit of code switching within a bilingual education program. Honors Projects. Retrieved from https://digitalcommons.iwu.edu/cgi/viewcontent.cgi?article=1002\&context=h ispstu_honproj

Redouane, R. (2005). Linguistic constraints on codeswitching and codemixing of bilingual Moroccan Arabic-French speakers in Canada (pp. 1921-1933). In ISB4: Proceedings of the 4th International Symposium on Bilingualism.

Romaine, S. (1989). Bilingualism. New York, NY: Basil Blackwell Inc.

Sebba, M., Mahootian, S., \& Jonsson, C. (Eds.). (2012). Language mixing and code-switching in writing: approaches to mixed-language written discourse. New York: Routledge. https://doi.org/10.4324/9780203136133

Senyatsi, K. K. (2012). An analysis of code switching as a learning and teaching strategy in selected multilingual schools of Limpopo Province. Doctoral dissertation. Retrieved from http://ulspace.ul.ac.za/bitstream/handle/10386/808/senyatsi_kk_2012.pdf?seq uence=1\&isAllowed=y

Skiba, R. (1997). Code switching as a countenance of language interference. The Internet TESL Journal, 3(10), 16.

TESOL. (2008). Position statement on English as a global language. Retrieved from http://www.tesol.org

Wardhaugh, R. (2006). An Introduction to Sociolinguistics (5th ed.). Malden, MA: Blackwell Publishing.

Weinreich, U. (1953). Languages in Contact. The Hague: Mouton

Zentella. A. (1997). Growing up Bilingual: Puerto Rican Children in New York. Oxford: Blackwell Publishers.

Zirker, K. A. H. (2007). Intrasentential vs. intersentential code switching in early and late bilinguals. Master's Thesis. Retrieved from All Theses and Dissertations. Retrieved from https://scholarsarchive.byu.edu/etd/927 


\section{Appendix A}

Professors' Questionnaire About Using "Code-switching strategy".

Name:

Years of experience in teaching English:

\begin{tabular}{|c|c|c|c|}
\hline No. & Statement & Agree & Disagree \\
\hline \multicolumn{4}{|c|}{ Perspectives and Attitude } \\
\hline & Do you agree or disagree with code-switching strategy used by professors in classroom? & & \\
\hline 2 & I think code switching strategy enhances the learning of the English language. & & \\
\hline 3 & I think code-switching strategy prevents the students from thinking and exploring by themselves. & & \\
\hline 4 & I think using a mixture of languages leads to the weakness of English 'students. & & \\
\hline 5 & I prevent students to switch since that will ruin their English vocabulary. & & \\
\hline 6 & I allow my students to switch to Arabic when they do not know the equivalents words in English. & & \\
\hline 7 & $\begin{array}{l}\text { I prefer to communicate with my students in both English and Arabic languages to make them feel confident in } \\
\text { explaining their ideas. }\end{array}$ & & \\
\hline \multicolumn{4}{|c|}{ The Nature and Reasons } \\
\hline & I only switch to Arabic when I want to direct my students, like "open the book", “write your assignment”. & & \\
\hline 9 & $\begin{array}{l}\text { I perceive ease of expression and more students are taking part in the classroom talk when me and my students switch } \\
\text { to Arabic in some situations. }\end{array}$ & & \\
\hline 10 & I use code-switching strategy to clarify information that is hard to deliver to the student when I use English language. & & \\
\hline 11 & I encourage the students to switch to Arabic in some situations. & & \\
\hline 12 & I use code-switching strategy to provide (perhaps unnecessary) explanation of some points. & & \\
\hline 13 & I use code-switching strategy to translate and clarify difficult vocabulary & & \\
\hline 14 & Code-switching strategy makes the students understand what I am explaining sufficiently. & & \\
\hline 15 & I use code-switching to make the lesson and the lecture easier to follow. & & \\
\hline 16 & I use code-switching strategy to boost students to participate. & & \\
\hline
\end{tabular}

\section{Appendix B}

Students' Questionnaire About Using "Code-switching strategy".

Name:

English level:

\begin{tabular}{llll}
\hline No. & Statement & Agree & Disagree \\
\hline 1 & Perspectives and Attitude & &
\end{tabular}

Do you agree or disagree with professors speaking your mother tongue as well as English in the classroom?”

2 I see code-switching as a valuable tool in classroom since it helps me to understand the complicated matter in easy way.

3 When the professor switches from English to Arabic, it effects on my English language proficiency.

4 When the professor switches from English to Arabic, he or she makes the lesson more complicated.

5 Code -switching enhances my learning of the English language

6 When the professor switches from English to Arabic, it helps me to participate and be more active in the class.

7 Using code-switching by professors saves my time and efforts to look for specific meaning.

8 I prefer professors using mixture of different languages.

9 The professors encourage us to use code switching in some situations.

10 Using code-switching in the classroom makes me sure that I am not losing any idea or information.

11 When the professor switches from English to Arabic, I consider him as a nonprofessional professor since he or she violates English classroom rules

12 I think when the professor switches from English to Arabic, he or she makes me feel that I am not sufficient enough to understand English.

I use code switching in the classroom when I'm unable to express myself in English.

14 I feel more comfortable when I communicate with my professors in English.

15 I switch to Arabic when I say words that I did not exposed to their equivalent in English.

\section{Copyrights}

Copyright for this article is retained by the author, with first publication rights granted to the journal.

This is an open-access article distributed under the terms and conditions of the Creative Commons Attribution license (http://creativecommons.org/licenses/by/4.0/). 